CLASSIFICATION CANCELLED

DATE MAR 141957

For The Atomic Energy Commission

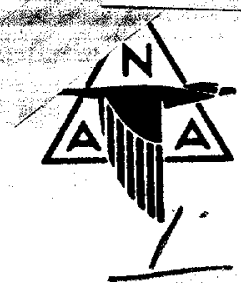

NAA-SR-895

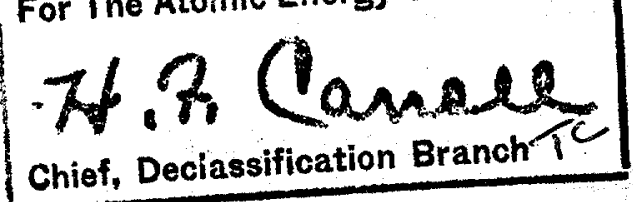

\title{
A PEBBLE-BED REACTOR FOR STATIONARY POWER PLANTS
}

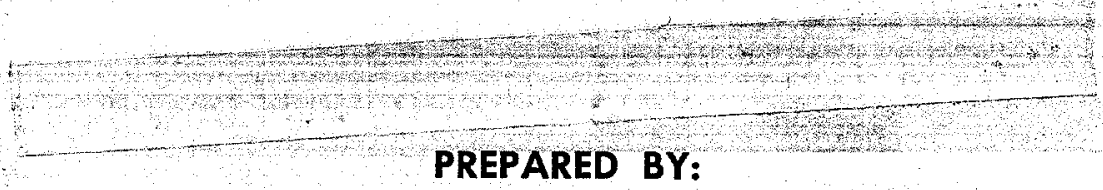

PREPARED BY:

\section{LEGAL NOTICE}

R. J. BEELEY

This report was prepared as an account of Government sponsored work. Neither the United States, nor the Commission, nor any person acting on behalf of the Commission:

A. Makes any warranty or representation, express or implied, with respect to the accuracy, completeness, or usefulness of the information contained in this report, or that the use of any information, apparatus, method, or process disclosed in this report may not infringe privately owned rights; or

B. Assumes any liabilities with respect to the use of, or for damages resulting from the use of any information, apparatus, method, or process disclosed in this report.

As used in the above, "person acting on behalf of the Commission" includes any employee or contractor of the Commission to the extent that such employee or contractor prepares, handles or distributes, or provides access to, any information pursuant to his employment or contract with the Commission.

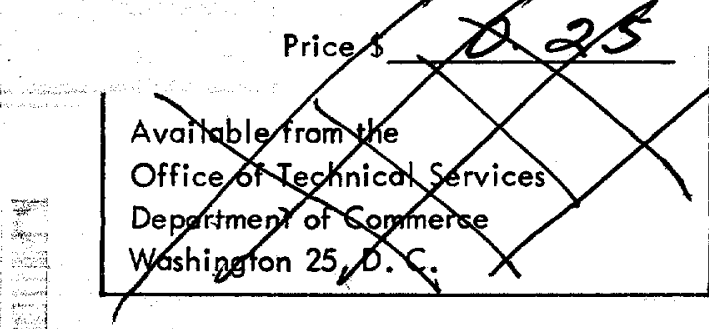
ATOMIC ENERGY RESEARCH DEPARTMENT NORTHAMERICAN AV I A I ION, INC. P. O. BOX 309 


\section{DISCLAIMER}

This report was prepared as an account of work sponsored by an agency of the United States Government. Neither the United States Government nor any agency Thereof, nor any of their employees, makes any warranty, express or implied, or assumes any legal liability or responsibility for the accuracy, completeness, or usefulness of any information, apparatus, product, or process disclosed, or represents that its use would not infringe privately owned rights. Reference herein to any specific commercial product, process, or service by trade name, trademark, manufacturer, or otherwise does not necessarily constitute or imply its endorsement, recommendation, or favoring by the United States Government or any agency thereof. The views and opinions of authors expressed herein do not necessarily state or reflect those of the United States Government or any agency thereof. 


\section{DISCLAIMER}

Portions of this document may be illegible in electronic image products. Images are produced from the best available original document. 
REPORT APPROVED BY:

\author{
A. B. MARTIN, Section Chief, Reactor Evaluation
}

S SIEGEL, Associate Director

C. STARR, Director

\title{
DISTRIBUTION
}

Category: REACTORS-RESEARCH AND
POWER

\author{
Standard Distribution
}

Copy No.

AF Plant Representative, Burbank

AF Plant Representative, Seattle

AF Plant Representative, Wood-Ridge

ANP Project Office, Fort Worth

Argonne National Laboratory

Armed Forces Special Weapons Project (Sandia)

Armed Forces Special Weapons Project, Washington

Atomic Energy Commission, Washington

Battelle Memorial Institute

Brookhaven National Laboratory

Bureau of Ships

California Patent Group

Carbide and Carbon Che rals Company (ORNL)

Carbide and Carbon $\mathrm{Ch}$ is Company ( $\mathrm{Y}-12$ Plant)

Chicago Patent Group

Chief of Naval Resea

Commonwealth Edi.

Department of the

Detroit Edison C

duPont Compan.

duPont Compa

Foster Whe e?

General Ele

General E]

Hanford $C$

Iowa Sta:

\author{
1
}

3

Los Alamos Scientif

Massachusetts Institute of Technology (Kaufmann)

Monsanto Chemical Company

Mound Laboratory

National Advisory Committee for Aeronautics, Cleveland

Naval Research Laboratory

New York Operations Office

Nuclear Development Associates, Inc.

Patent Branch, Washingion

Phillips Petroleum Company

Powerplant Laboratory (WADC)

Pratt \& Whitney Aircraft Division (Fox Project)

RAND Corporation

San Francisco Field Office

Sylvania Electric Products, Inc.

USAF Headquarter $s$

U. S. Naval Radiological Defense Laboratory

University of California Radiation Laboratory, Berkeley

University of California Radiation Laboratory, Livermore

Walter Kidde Nuclear Laboratories, Inc.

Westinghouse Electric Corporation

Technical Information Service, Oak Ridge File 


\section{TABLE OF CONTENTS}

Page No.

Abstract . . . . . . . . . . . . . . . . . 4 4

I. Introduction . . . . . . . . . . . . . . . . . 5

II. Analyses . . . . . . . . . . . . . . . . . . 5

A. Core Calculations . . . . . . . . . . . . . 5

B. Reactor Power and Critical Mass . . . . . . . . . . 11

C. Maximum Graphite Sphere Diameter . . . . . . . . 12

D. Coolant Pressure Drop in Core. . . . . . . . . . 14

E. Rough Cost Estimate ... . . . . . • . . . . • 16

III. Conclusions . . . . . . . . . . . . . . . . . 18

References • • • • • • . • • • • • . • . . 22

\section{LIST OF FIGURES}

1. Thorium Resonance Integral vs Scattering Cross Section ....

2. Resonance Escape Probability vs Thorium Concentration in Graphite. • . . . • . . . . . . . . . . . . 19

3. Multiplication Factors vs Thorium Concentration in Graphite . . 20

4. Materials Buckling vs Thorium Concentration . . . . . . . 20

5. Zero-Flux Breeding Ratio vs Thorium Concentration. . . . . 21

6. Core Diameter vs Breeding Ratio . . . . . . . . . . . 21 


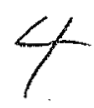

\section{ABSTRACT}

A preliminary study has been made of a solid homogeneous reactor for stationary power plant application. The core consists of graphite spheres impregnated with uranium and thorium, and the coolant is bismuth. This concept possibly offers advantages over other solid fuel reactor systems with respect to simplification of core structure; fuel fabrication and fuel handling, and reduction of fuel inventory external to the reactor. From the results of this preliminary study, it appears that the potential cost of electric power from this reactor is competitive with that from other reactor systems which have been proposed for the same application. The Po 210 produced in the coolant presents a decontamination problem, but is also possibly a valuable by-product.

This report is based on studies made for the Atomic Energy Commission under Contract AT-11-1-GEN-8.
\end{abstract}

503003 


\section{INTRODUCTION}

The features of a pebble bed reactor which may make it attractive for power generation are (1) a relatively simple core with essentially no precise machining required, (2) the possibility of simple fuel handling procedures, and (3) a minimum of fuel held outside the reactor core.

The design of the system discussed here is conceptual only. The core consists of a bed of graphite spheres impregnated with uranium and thorium and cooled with bismuth. Carman has shown that the void fraction in a bed of randomly packed spheres is about 0.37 when the sphere diameter is small compared to the container dimensions. In the reactor core this void is filled with coolant, and bismuth was selected as the only liquid metal which could give reasonable neutron economy; a bismuth volume fraction of 40 per cent was assumed for the core calculations. A two-foot graphite reflector was assumed, and the reactor container and piping are of a medium chrome steel. Control is by means of absorber rods operating in closed beryllium thimbles which extend through the core.

The graphite spheres are approximately 3 inches in diameter, limited by tensile thermal stress at the sphere surface; the largest sphere possible is desirable to reduce the coolant pressure drop in the core. The spheres would float in the bismuth, constituting a mobile fuel which could be readily removed.

\section{ANALYSES}

\section{A. CORE CALCULATIONS}

The calculations assume steady-state concentrations of $\mathrm{U}^{233}, \mathrm{U}^{234}$, $\mathrm{U}^{235}$ and $\mathrm{U}^{236}$. The concentration of $\mathrm{Pa}^{233}$ is a function of the local flux level and therefore varies with position in the core, making rigorous calculations difficult. In this preliminary investigation the effect of $\mathrm{Pa}^{233}$ on reactivity and breeding ratio was neglected, and the reactor power was computed assuming a riaximum thermal neutron flux of $10^{14}$ neutrons $/ \mathrm{cm}^{2}-\mathrm{sec}$. With this flux, less than 3 per cent of the $P a$ formed in the center of the core would absorb neutrons before decaying to $\mathrm{U}^{233}$. Poisoning by saturated concentrations of Xe and $\mathrm{Sm}$ was included.

503004 
The calculations were based on a homogeneous model, and fast effect assumed to be unity. In steady state the relative concentrations and absorptions in the various isotopes are as follows:

$$
\begin{aligned}
& \frac{N_{24}}{N_{23}}=\frac{\sigma_{c 23}}{\sigma_{a 24}}=0.561 \quad \frac{\sum_{a 24}}{\sum_{a 23}}=\frac{\sigma_{c 23}}{\sigma_{a 23}}=0.0887 \\
& \frac{N_{25}}{N_{23}}=\frac{\sigma_{c 23}}{\sigma_{a 25}}=0.0725 \quad \frac{\sum_{a 25}}{\sum_{a 23}}=\frac{\sigma_{c 23}}{\sigma_{a 23}}=0.0887 \\
& \frac{N_{26}}{N_{23}}=\frac{\sigma_{\mathrm{c} 25} \quad \sigma_{\mathrm{c} 23}}{\sigma_{\mathrm{a} 26} \sigma_{\mathrm{a} 25}}=0.857 \quad \frac{\sum_{\mathrm{a} 26}}{\sum_{\mathrm{a} 23}}=\frac{\sigma_{\mathrm{c} 23} \sigma_{\mathrm{c} 25}}{\sigma_{\mathrm{a} 23} \sigma_{\mathrm{a} 25}}=0.0137 \\
& \frac{\sum_{\mathrm{p}}}{\sum_{\mathrm{a} 23}}=0.073\left(\frac{\sum_{\mathrm{f} 23}}{\sum_{\mathrm{a} 23}}+\frac{\sum_{\mathrm{a} 25}}{\sum_{\mathrm{a} 23}}\right) \simeq 0.073
\end{aligned}
$$

where $\Sigma_{p}$ is the absorption cross section of Xe and Sm. Defining $\Sigma_{\text {au }}$ as the sum of the absorption cross section of all the uranium isotopes plus the important fission product poisons, we have

$\Sigma_{\text {au }}=1.2641 \Sigma_{\text {a23 }}$

Define $\eta=\frac{\eta 23^{\Sigma_{a 23}+\eta 25} \sum_{a 25}}{\Sigma_{\mathrm{au}}}$

$$
\text { and } f=\frac{\sum_{a u}}{\sum_{a u}+\sum_{a t h}+\sum_{a B i}+\Sigma_{a c}}
$$

then $\eta \mathrm{f}=\frac{\eta_{23} \Sigma_{\mathrm{a} 23}+\eta_{25} \Sigma_{a 25}}{\sum_{\mathrm{au}}+\Sigma_{\mathrm{ath}}+\Sigma_{\mathrm{aBi}}+\Sigma_{\mathrm{ac}}}$

$$
=\frac{2.505}{1.2641+0.01241 \mathrm{y} / \mathrm{x}+1.35 \times 10^{-5} \mathrm{y}+7.98 \times 10^{-6} \mathrm{y}}
$$

where $y=N_{c} / N_{23}$

$$
x=N_{c} / N_{t h}
$$

\section{$503 \quad 005$}


These figures are based on the following constants; the absorption cross sections assume a neutron temperature of $600^{\circ} \mathrm{C}$ :

$\begin{array}{ll}\quad \text { Absorption } & \underline{\text { Total }} \\ \sigma_{\mathrm{c} 23}=25.7 \text { barns } & \sigma_{23}=297 \text { barns } \\ \sigma_{\mathrm{a} 23}=289 \text { barns } & \sigma_{24}=54 \text { barns } \\ \sigma_{\mathrm{a} 24}=45.6 \text { barns } & \sigma_{25}=365 \text { barns } \\ \sigma_{\mathrm{c} 25}=54.9 \text { barns } & \sigma_{26}=13 \text { barns } \\ \sigma_{\mathrm{a} 25}=355 \text { barns } & \sigma_{\mathrm{th}}=16.9 \text { barns } \\ \sigma_{\mathrm{a} 26}=4.6 \text { barns } & \sigma_{\mathrm{m}}=4.8 \text { barns } \\ \sigma_{\mathrm{ath}}=3.94 \text { barns } & \sigma_{\mathrm{Bi}}=9.0 \text { barns } \\ \sigma_{\mathrm{ac}}=2.31 \text { millibarns } & \eta_{23}=2.32 \\ \sigma_{\mathrm{aBi}}=16.4 \text { millibarns } & \eta_{25}=2.09\end{array}$

The resonance escape probability was computed from the expression $p=\exp \left[-\frac{N_{t h}}{\xi \Sigma_{s}}\left(\int_{E_{t h}}^{E_{o}} \sigma_{a \text { eff }} \frac{d E}{E}+11\right)\right]$ where $\overline{\xi \Sigma_{s}}=\overline{\xi_{c} \Sigma_{s c}}+{\overline{\xi_{B i}}}_{s B i}$

and 11 barns is the $1 / v$ contribution to the resonance absorption. The scattering cross section of graphite and bismuth were taken to be 4.3 and 9.0 barns, respectively in the resonance region. With densities of 1.6 and 9.8 for the graphite and bismuth:

$$
\bar{\xi}_{\mathrm{s}}=0.0356
$$

With $\mathrm{N}_{\text {th }}=\mathrm{N}_{\mathrm{c}} / \mathrm{x}=0.0502 \times 10^{24} / \mathrm{x}$, the expression for $\mathrm{p}$ becomes:

$$
p=\exp \left[-\frac{1}{0.71 x}\left(\int_{E_{\text {th }}}^{E_{0}} \sigma_{\text {aeff }} \frac{d E}{E}+11\right)\right]
$$

$$
503
$$


The resonance integral for thorium was approximated by the expression

$$
\int_{E_{t h}}^{E_{0}} \sigma_{\text {aeff }} \frac{d E}{E}=\frac{\left(\int_{t h}^{E_{0}} \sigma_{a e f f} \frac{d E}{E}\right)_{\infty}}{\left(1+\frac{\sigma_{0}}{\sigma_{s}}\right)^{1 / 2}}=\frac{70}{\left(1+\frac{\sigma_{0}}{\sigma_{s}}\right)^{1 / 2}}
$$

where the integral in the numerator is the value for infinite dilution of thorium, and $\sigma_{s}$ is the total scattering cross section per atom of thorium. The constant $\sigma_{0}$ is determined by using the figure of 12 barns for the integral for pure metallic thorium; in this case $\sigma_{s}=\sigma_{\text {sth }}=13$ barns.

$$
\frac{70}{\left(1+\frac{\sigma_{\mathrm{o}}}{\sigma_{\mathrm{sth}}}\right)^{1 / 2}}=12 ; \quad \sigma_{\mathrm{o}}=429
$$

A curve of the value of the resonance integral vs scattering cross section per thorium atom appears in Fig. 1. The resonance escape probability for the system under consideration is plotted in Fig. 2 as a function of the carbon-tothorium atom ratio; the lower curve shows the decrease in $p$ when the bismuth coolant is drained from the core.

In Fig. 3 the multiplication constant for the core is plotted against $x=N_{m} / N_{t h}$, for three values of the parameter $y=N_{m} / N_{23}$. The thermal diffusion length $L$ was computed from the expression

$$
1 / L^{2}=3 \sum_{\mathrm{a}} \Sigma_{\mathrm{T}}
$$

where $\Sigma_{a}$ and $\Sigma_{T}$ are the absorption and total cross sections for the combination of core materials.

The Fermi age for the core is defined by

$$
\tau=\int_{E_{t h}}^{E_{0}} \frac{D d E}{\xi \sum_{S} E}
$$

In order to evaluate $\tau$, the age in graphite and that in bismuth were first determined in order to compute average constants for the above expression.

$$
-503 \quad 007
$$


BNL 170 gives $311 \mathrm{~cm}^{2}$ for the age in graphite of density $1.6 \mathrm{gm} / \mathrm{cm}^{3}$, from fission energies to indium resonance (1.44 ev). The increment from 1.44 ev to thermal $\left(600^{\circ} \mathrm{C}\right), 0.0755 \mathrm{ev}$, , can be computed with fair accuracy:

$$
\begin{aligned}
& \Delta \tau_{c}=\int_{0.0755}^{01.44 \mathrm{ev}} \frac{\mathrm{D}}{\xi \sum_{\mathrm{s}}} \frac{\mathrm{dE}}{\mathrm{E}} \simeq \frac{\ln \frac{1.44}{0.0755}}{3 \sum_{\mathrm{tr}} \sum_{\mathrm{s}} \xi} \simeq \frac{2.95}{3 \sum_{\mathrm{s}}^{2}\left(1-\bar{\mu}_{\mathrm{o}}\right) \xi}=42 \mathrm{~cm}^{2} \\
& \tau_{c}=311+42=353 \mathrm{~cm}^{2}
\end{aligned}
$$

The age in bismuth, $\tau_{\mathrm{Bi}}$, was computed by numerical integration of the expression for $\tau$ from $2 \times 10^{6}$ ev to $0.0755 \mathrm{ev}$. The result is $11,000 \mathrm{~cm}^{2}$ for pure bismuth.

To compute the Fermi age for the graphite-bismuth mixture, average scattering cross sections were computed as follows:

$$
\text { carbon } \bar{\sigma}_{s}^{2}=\frac{\ln \left(2 \times 10^{6} / 0.0755\right)}{3 \xi_{c} N_{c}^{2}\left(1-\bar{\mu}_{0}\right) \tau_{c}} \quad \text { (pure graphite) }
$$$$
\text { bismuth } \bar{\sigma}_{\mathrm{s}}^{2}=\frac{\ln \left(2 \times 10^{6} / 0.0755\right)}{3 \xi_{\mathrm{Bi}} N_{\mathrm{Bi}}^{2}\left(1-\overline{\mu_{\mathrm{o}}}\right) \tau_{\mathrm{Bi}}} \quad \text { (pure bismuth) }
$$

where $2 \times 10^{6}$ ev has been chosen as an average ta $t$ neutron energy. These calculations give:

$$
\begin{aligned}
& \bar{\sigma}_{\mathrm{sc}}=4.0 \text { barns } \\
& \bar{\sigma}_{\mathrm{sBi}}=7.8 \text { barns. }
\end{aligned}
$$

The age in the core mixture is then computed from

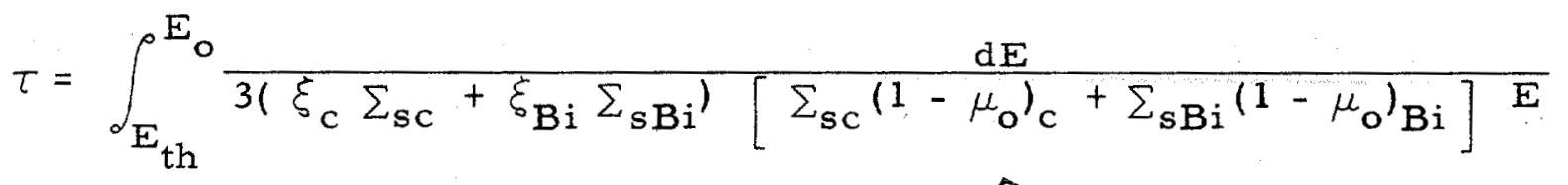
$5_{0}$ 
$\tau \simeq \frac{\ln \left(E_{o /} E_{t h}\right)}{3\left[\xi_{c} \bar{\Sigma}_{S C}+\xi_{B i} \bar{\Sigma}_{S B i}\right]\left[\bar{\Sigma}_{S C}\left(1-\mu_{o}\right)_{c}+\bar{\Sigma}_{S B i}\left(1-\mu_{o}\right)\right.}$

$\tau=640 \mathrm{~cm}^{2}$ when the constants are inserted.

Since the reactors are large, the buckling, $\mathrm{B}^{2}$, was obtained from the expression

$$
B^{2}=\frac{K_{\infty}-1}{L^{2}+\tau}
$$

Curves of buckling appear in Fig. 4.

The breeding ratio for the system was computed from

$$
\text { B. R. }=\frac{\sum_{a t h}}{\sum_{a 23}}+2.505(1-p) e^{-B^{2} \tau}
$$

Because the resonance escape probability, $p$, is low in these homogeneous systems, the thermal contribution to the breeding ratio is small. Curves of the breeding ratio appear in Fig. 5. It should be noted that the breeding ratio as defined is a "zero flux" breeding ratio in that it neglects the burnout of $\mathrm{Pa}{ }^{233}$. The absorption cross section of $\mathrm{Pa}^{233}$ as reported in $\mathrm{TID}-2010^{2}$ is $152 \mathrm{~b}$ for 0.0253 ev neutrons; the effective cross section in this reactor system is $152 \sqrt{\frac{293^{\circ}}{873^{\circ}} \times \frac{\sqrt{\pi}}{2}}=78 \mathrm{~b}$, assuming $1 / v$ variation with neutron energy. With this cross section burnout will cause a loss of 2.7 per cent of the $\mathrm{Pa}^{233}$ per $10^{14}$ neutrons $/ \mathrm{cm}^{2}-\mathrm{sec}$.

Curves of critical size vs breeding ratio appear in Fig. 6. In making these calculations, the core height was held constant at 12 feet, and a reflector savings of 45 centimeters on all surfaces was assumed.

Three reactors with a breeding ratio of unity, as defined above, were selected for determination of power output, maximum graphite sphere diameter and coolant pressure loss. These three reactors have the following characteristics:

\section{9}

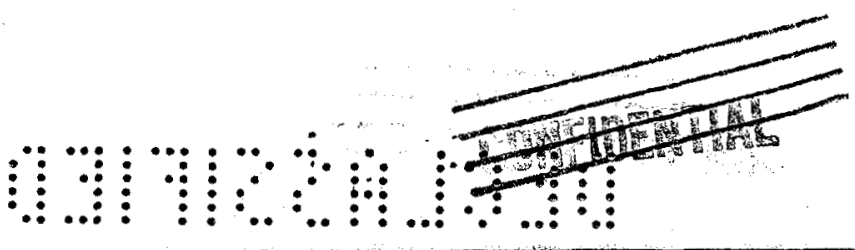


Reactor

1

2

3

$\frac{y=N_{c} / N_{23}}{2000} \cdot \frac{x=N_{c} / N_{t h}}{203}$

\begin{tabular}{|c|c|}
\hline $\mathrm{B}^{2} \times 10^{6}$ & Core radius, $\mathrm{ft}$ \\
\hline 120 & 7.8 \\
\hline 111 & 8.5 \\
\hline 103 & 9.1 \\
\hline
\end{tabular}

\section{B. REACTOR POWER AND CRITICAL MASS}

The reactor thermal power is computed assuming a maximum thermal flux of $10^{14}$ to avoid excessive loss of $\mathrm{U}^{233}$ production by $\mathrm{Pa}^{233}$ burnout. The fission cross section is given by

$$
\begin{aligned}
\Sigma_{f} & =N_{23} \sigma_{f 23}+N_{25} \sigma_{f 25}=N_{23}\left(\sigma_{f 23}+0.0725 \sigma_{f 25}\right) \\
& =\frac{N_{c}}{y}\left(\sigma_{f 23}+0.0725 \sigma_{f 25}\right)
\end{aligned}
$$

$\Sigma_{f}=\frac{13.7}{y}$ when the constants are inserted and the assumption made that the bismuth volume fraction is 40 per cent.

The over-all average/peak power generation is given by:

$$
\operatorname{avg} / p k=\frac{4 L_{0}}{\pi \mathrm{L}} \sin \left(\frac{\pi}{2} \frac{L}{L_{0}}\right) \frac{J_{1}\left(2.405 R / R_{0}\right)}{2.405 R / R_{0}}
$$

The power in $\mathrm{mw}$ is then

$$
P=\frac{\sum_{f} \times 10^{14} \times \mathrm{avg} / \mathrm{pk} \times \mathrm{V}}{3.18 \times 10^{16}}
$$

where $V$ is the core volume in $\mathrm{cm}^{3}$ and $3.18 \times 10^{16}$ fissions/sec equals $1 \mathrm{mw}$.

The critical mass $M_{c}$, is a simple function of the core volume and fuel concentration. The figures for the three breeders are as follows:

503<smiles>[Os]</smiles> 


\begin{tabular}{|c|c|c|c|c|}
\hline Reactor & $y=N_{c} / N_{23}$ & Power - mw & $\mathrm{M}_{\mathrm{c}}-\mathrm{Kg}$ of $\mathrm{U}^{233}$ & $\begin{array}{c}\text { Specific Power } \\
\mathrm{Kw} / \mathrm{gm} 23\end{array}$ \\
\hline 1 & 2000 & 558 & 602 & 0.925 \\
\hline 2 & 2500 & 514 & 570 & 0.901 \\
\hline 3 & 3000 & 492 & 550 & 0.895 \\
\hline
\end{tabular}

\section{MAXIMUM GRAPHITE SPHERE DIAMETER}

Because graphite is weakest in tension, the thermal stress of interest is the tangential stress at the surface of the sphere. This stress is given by ${ }^{3}$

$$
\sigma(b)=\frac{a E}{1-\nu}\left[\frac{3}{b^{3}} \int_{0}^{b} T(r) r^{2} d r-T(b)\right]
$$

where $\sigma(b)$ is the tensile stress at $r=b$, the radius of the sphere

$$
\begin{aligned}
\alpha & =\text { coefficient of thermal expansion } \\
\mathrm{E} & =\text { Young's modulus } \\
\nu & =\text { Poisson's ratio } \\
\mathrm{T}(\mathrm{r}) & =\text { temperature inside the graphite sphere }
\end{aligned}
$$

In this expression the graphite temperature is assumed to be a function of the radius only. If the thermal conductivity $k$, is assumed constant, the temperature distribution is given by

$$
T(r)=\frac{q}{6 k}\left(b^{2}-r^{2}\right)+T(b)
$$

where $q$ is the power density in the graphite. With this expression for $T(r)$ the thermal stress at the sphere's surface is

$$
\sigma(b)=\frac{a E b^{2} q}{15 k(1-v)}
$$

and the maximum sphere radius $b_{m}$, is given by:

$$
\mathrm{b}_{\mathrm{m}}^{2}=\frac{15 \mathrm{k}(1-\nu) \sigma_{\max }}{\alpha E \mathrm{q}_{\max }}
$$

Conservative figures for the physical constants were obtained from the Materials Handbook ${ }^{4}$ as follows:

$$
\alpha=3.0 \times 10^{-6} \text { in. /in. }-{ }^{\circ} \mathrm{F}
$$

\section{$503 \quad 011$}

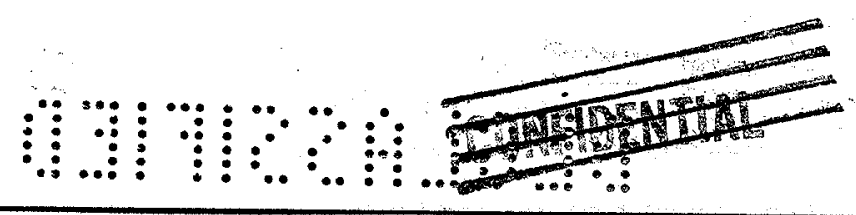




$$
\begin{aligned}
\mathrm{E} & =0.85 \times 10^{6} \mathrm{psi} \\
\nu & =0.2 \\
\mathrm{k} & =24 \mathrm{btu} / \mathrm{hr}-\mathrm{ft}-^{\circ} \mathrm{F} \\
\sigma_{\max } & =1300 \mathrm{psi}
\end{aligned}
$$

The conductivity, $\mathrm{k}$, was reduced to $8 \mathrm{Btu} / \mathrm{hr}-\mathrm{ft}-{ }^{\circ} \mathrm{F}$ to account for radiation damage to the graphite. With these constants the maximum sphere radius is

$$
b_{m}=\frac{221}{\sqrt{q_{m}}},(f t)
$$

The maximum power densities, $q_{m}$, at the center of the cores of the reactors under consideration are $3.48,2.71$ and $2.24 \times 10^{6} \mathrm{Btu} / \mathrm{hr}-\mathrm{ft}^{3}$ for the carbon to $\mathrm{U}^{233}$ ratios of 2000,2500 and 3000 , respectively, and a maximum flux of $10^{14}$ neutrons $/ \mathrm{cm}^{2}-\mathrm{sec}$. The corresponding sphere diameters are $2.85,3.21$ and 3.53 inches.

The coolant temperatures are determined by the properties of the materials used. The melting point of bismuth is $520^{\circ} \mathrm{F}$, and some margin is required on the inlet temperature. The coolant outlet temperature is determined by the strength and oxidation of the containers and piping; these would probably be of a medium chrome steel which has reasonable strength and resistance to oxidation up to about $1100^{\circ} \mathrm{F}$.

Assuming bismuth inlet and outlet temperatures of $662^{\circ} F\left(350^{\circ} \mathrm{C}\right)$ and $1022^{\circ} \mathrm{F}\left(550^{\circ} \mathrm{C}\right)$, the average temperature of a graphite sphere at the center of the core is $1252^{\circ} \mathrm{F}$, determined by integrating $T(r)$ over the volume of the sphere; this average temperature is independent of the sphere diameter, depending onfy upon the maximum allowable tensile stress, Poisson's ratio, Young's modulus and the temperature of the surface. In these calculations, film drop from the graphite sphere to the bismuth coolant was neglected.

The thermal conductivity of graphite as given in the Materials Handbook can be approximated quite well over the range of interest by an expression of the type $\mathrm{k}=\mathrm{a} / \mathrm{T}$, where $\mathrm{a}$ is a constant and $\mathrm{T}$ the absolute temperature; with this type of dependence the temperature distribution in the sphere is exponential rather than parabolic:

$$
T(r)=T(b) e^{\frac{q}{b a}\left(b^{2}-r^{2}\right)}
$$

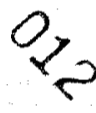


and the expression for tangential stress at the surface of the sphere is:

$$
\begin{aligned}
& \sigma(b)=\frac{T(b) a E}{1-\nu} \quad\left[\frac{3 \sqrt{\pi} e^{c^{2}}}{2 c^{3}} \operatorname{erf}(\sqrt{2} c)-\frac{3}{2 c^{2}}-1\right] \\
& \text { where } c^{2}=\frac{q b^{2}}{6 a} \\
& \operatorname{erf} x=\frac{1}{\sqrt{2 \pi}} \int_{0}^{x} e^{-t^{2} / 2} d t
\end{aligned}
$$

When $\mathrm{k}$ is given in degrees Rankine (absolute Fahrenheit), the constant a is $13,800 \mathrm{Btu} / \mathrm{hr}-\mathrm{ft}$. Substituting the constants in the above expression for $\sigma$ (b) and again assuming $\sigma_{\max }=1300 \mathrm{psi}$, the solution is $\mathrm{c}^{2}=0.64$ or

$$
b_{m}=\frac{\sqrt{6 a} c}{\sqrt{q_{m}}}=\frac{230}{\sqrt{q_{m}}}(\mathrm{ft})
$$

The maximum sphere diameter is thus not essentially different from that obtained when the conductivity was assumed constant. The average temperature of a graphite sphere, given by

$$
\begin{aligned}
\bar{T} & =\frac{3 T(b)}{2 c^{2}}\left[\frac{e^{c^{2} \sqrt{\pi}} \operatorname{erf}(\sqrt{2} c)}{c}-1\right] \\
& =1710^{\circ} \mathrm{R} \\
\bar{T} & =1250^{\circ} \mathrm{F}
\end{aligned}
$$

is also practically the same as for the parabolic temperature distribution.

The graphite temperature varies considerably throughout the reactor core because of the changes in coolant temperature and because of the variation in $q$, the power density in the graphite, with position in the core. A sphere for which $\mathrm{q}=1 / 2 \mathrm{q}_{\max }$ would have an average temperature about $200^{\circ} \mathrm{F}$ above the coolant temperature which has an average value of about $840^{\circ} \mathrm{F}$. For the reactor physics calculations a mean graphite temperature of $1112^{\circ} \mathrm{F}\left(600^{\circ} \mathrm{C}\right)$ was as sumed.

\section{COOLANT PRESSURE DROP IN CORE}

An expression for calculating the pressure drop of a fluid flowing through a bed of uniform solid particles is given in the Chemical Engineer's Handbook: 


$$
p=\frac{4 \mathrm{fL} \rho \mathrm{V}_{\mathrm{o}}^{2} \mathrm{~A}_{\mathrm{f}}}{2 \mathrm{gD} \mathrm{D}_{\mathrm{p}}}
$$

where $f=$ friction factor $=38 / \mathrm{N}_{\mathrm{Re}}^{0.15}$

$\mathrm{N}_{\mathrm{Re}}=$ modified Reynolds number $=\frac{\rho \mathrm{V}_{\mathrm{o}} \mathrm{D}_{\mathrm{p}}}{\mu}$

$\rho=$ fluid density $1 \mathrm{~b} / \mathrm{ft}^{3}$ (assumed constant)

$V_{0}=$ fluid velocity based on empty tube area; i.e., velocity with pebbles removed, ft/sec

$\mathrm{D}_{\mathrm{p}}=$ diameter of pebbles, $\mathrm{ft}$

$\mu=$ fluid viscosity, $1 \mathrm{~b} / \mathrm{ft}-\mathrm{sec}$ (assumed constant)

$\mathrm{L}=$ length of bed, ft

$A_{f}=$ wall effect factor (curve in Handbook)

$\mathrm{g}=$ accel. of gravity, $\mathrm{ft} / \mathrm{sec}^{2}$.

The fluid velocity depends upon the temperature rise of the coolant $\left(360^{\circ} \mathrm{F}\right)$, the reactor power and the specific heat, $c_{p}$, of liquid bismuth. Values of the physical "properties of liquid bismuth were taken from the Liquid Metals Handbook. ${ }^{6}$

$$
\begin{aligned}
& c=0.023 \mathrm{Btu} / 1 \mathrm{~b}-{ }^{\circ} \mathrm{F} \\
& \rho=6101 \mathrm{~b} / \mathrm{ft}^{3} \\
& \mu=0.0008351 \mathrm{~b} / \mathrm{ft}-\mathrm{sec} .
\end{aligned}
$$

The wall effect factor, $A_{f}$, is a function of the ratio of the pebble diameter to the tube (core) diameter, and is approximately 0.93 for the three breeder reactors under consideration.

Using the figures for pebble diameter, etc., previously determined, the pressure drops for the three breeder reactors are 31,17 and 11 psi for the cores with carbon to $\mathrm{U}^{233}$ atomic ratios of 2000,2500 and 3000 , respectively. These

\begin{tabular}{|c|c|c|c|c|c|}
\hline Reactor & $\mathrm{N}_{\mathrm{c}} / \mathrm{N}_{23}$ & Core Radius, & $\begin{array}{c}\text { Pebble Diameter } \\
\text { in. }\end{array}$ & $\begin{array}{c}\text { Core Pressure } \\
\text { psi }\end{array}$ & Drop, \\
\hline 1 & 2000 & 7.8 & 2.9 & 31 & \\
\hline 2 & 2500 & 8.5 & 3.2 & 17 & \\
\hline 3 & 3000 & 9.1 & 3.5 & $O_{7}$ & \\
\hline
\end{tabular}
figures for pressure drop must be regarded as approximate only.

A summary of the results of calculations for the three breeder reactors is as follows: 
The cooling system and steam plant have not been analyzed carefully; the bismuth inlet and outlet temperatures are somewhat higher than the corresponding temperature for the sodium-graphite system of NAA-SR-180, ${ }^{7}$ which has a net thermal efficiency of about 30 per cent. The bismuth temperatures are sufficiently high that any steam pressure up to the critical point could be used; the best steam conditions have not been determined, but a net thermal efficiency of 32 per cent is assumed. For the rough cost estimate of the next section, the thermal power of reactor No. 2 was taken to be $500 \mathrm{mw}$ (computed $514 \mathrm{mw}$ ), giving a net electrical output of $160 \mathrm{mw}$.

\section{E. ROUGH COST ESTIMATE}

There is no detailed design of this reactor system, and a realistic cost estimate is impossible; however, a very rough estimate can be derived, making use of cost data for other systems which are more completely detailed such as the sodium-graphite reactor plant. The reactor dimensions used in this estimate are those of the reactor with a breeding ratio of unity and a carbon/ ${ }^{233}$ ratio of 2500 (Reactor No. 2). The fuel investment charge is made on the critical mass of $\mathrm{U}^{235}$ required to start the reactor plus an additional 50 per cent outside the core. The critical mass of clean $U^{235}(575 \mathrm{~kg})$ is essentially the same as the steady-state critical mass of $\mathrm{U}^{233}$, but the conversion ratio is only 0.83 , so that make-up fuel is required initially.

\section{POWER COST ESTIMATE}

500 Thermal MW 160 Electrical MW
$80 \%$ Plant Factor $-1.12 \times 10^{9} \mathrm{kwh} / \mathrm{yr}$

Reactor

Power Plant (120/kw)

Fuel $(\$ 30 / \mathrm{gm})$

Fuel Feed (initially) -
Investment Rate Annual Cost Mils/kwh

$\begin{array}{rrrr}\$ 13 \times 10^{6} & 15 \% & \$ 1,950,000 & 1.74 \\ 19.2 \times 10^{6} & 15 \% & 2,880,000 & 2.57 \\ 25.8 \times 10^{6} & 12 \% & 3,100,000 & 2.77 \\ 31 \mathrm{~kg} / \mathrm{yr} @ & 930,000 & 0.83 \\ & \$ 30 / \mathrm{gm} & & \end{array}$

Fuel Processing

$1,070,000$

1.00

Gen. Operation and Maintenance $\frac{0.96}{9.87}$

The reactor is not an especially large item in the cost of power, and

a large error in the cost of the reactor does not produce a very large error 16 $503^{015}$ 
in the cost of power; uncertainties in the costs of the site, fuel processing and in operation and maintenance are at least as important as the uncertainty in the reactor cost.

The figures of the table apply to start-up conditions when $U^{235}$ must be fed to the system to maintain reactivity. This feed requirement decreases to zero as the $\mathrm{U}^{235}$ is replaced by $\mathrm{U}^{233}$.

The cost of fuel processing includes fabrication and impregnation of the graphite spheres as well as recovery of the uranium and thorium from spent fuel; this recovery would require Thorex processing. Impregnation of graphite with uranium has been accomplished at NAA on a laboratory scale; the costs of this operation on a large scale and of the recovery steps are not known, and the figure in the table is simply a reminder that this expense will exist. It is possible that the spheres could be reused by simply driving off most of the fission products by heating the spheres in a vacuum.

The figure for operation and maintenance of the plant is based on a yearly cost of $\$ 1.25 / \mathrm{kw}$ of capability for operation and $11 / 2$ per cent of the capital investment for maintenance.

The largest single item is the fuel investment charge. The fuel feed cost even with $U^{235}$ fuel is considerably smaller, which indicates that limitation of the neutron flux to permit breeding in the steady state is probably not the economic thing to do; i.e., the cost of power would be lower if the reactor did not breed. For example, if the power level were doubled by increasing the maximum flux to $2 \times 10^{14}$, the cost of the reactor and fuel investments would be approximately halved, and the fuel feed cost would increase by less than 0.2 $\mathrm{mils} / \mathrm{kwh}$.

The reactor produces relatively large quantities of polonium-210 which could be a valuable by-product. The current price of $\mathrm{Po}^{210}$ is quoted ${ }^{8}$ as $\$ 2410$ plus $\$ 100 /$ c for plated sources. One gram of $\mathrm{Po}^{210}$ has an activity of nearly 4500 curies. 'The reactor produces about $16 \mathrm{gms} /$ day; if 80 per cent of this is marketable at $\$ 0.25 /$ curie, the Po ${ }^{210}$ would be worth $\$ 14,400 /$ day. In terms of power cost this is nearly $5 \mathrm{mils} / \mathrm{kwh}$, which would cut the estimated cost of power in half. The polonium can be readily removed from the bismuth by distillation or by contacting the bismuth with molten $\mathrm{N} \theta \mathrm{H}$, provided the polonium is not absorbed into the graphite in the reactor. 


\section{CONCLUSIONS}

As a heat source for a stationary power plant, it is difficult to state, on the basis of this investigation, whether this type reactor is better or poorer than other types proposed. A rough cost estimate indicates that it is potentially competitive with other reactor systems that have been proposed for this application. One immediately obvious disadvantage of the system is that breeding is difficult to achieve. This is the result of the large slowing down area, $\tau$.

It is of interest to draw comparisons between this reactor and the Brookhaven LMFR ${ }^{9}$ which it most nearly resembles. The LMFR has the uranium fuel dissolved in the bismuth coolant, and in the Project Dynamo ${ }^{10}$ version, all breeding takes place in a blanket surrounding the core; the fertile material is in the form of a Th-Bi compound in liquid Bi. The LMFR has most of its fuel solution outside the core, but the fuel inventory is smaller than that for the pebble bed system. The liquid fuel is more readily handled and processed than the graphite spheres, and a breeding ratio of unity can be achieved in a small reactor; a high specific power can be obtained with the LMFR since Pa ${ }^{233}$ burnout is not a serious problem.

The only advantage the pebble bed reactor may have over the LMFR is that of more immediate feasibility; the problems of keeping the uranium in solution and of obtaining a stable suspension in the breeding blanket of the LMFR are avoided. It is entirely possible that this advantage is illusory, born of ignorance of the problems associated with the pebble-bed system.

$503 \quad 017$ 

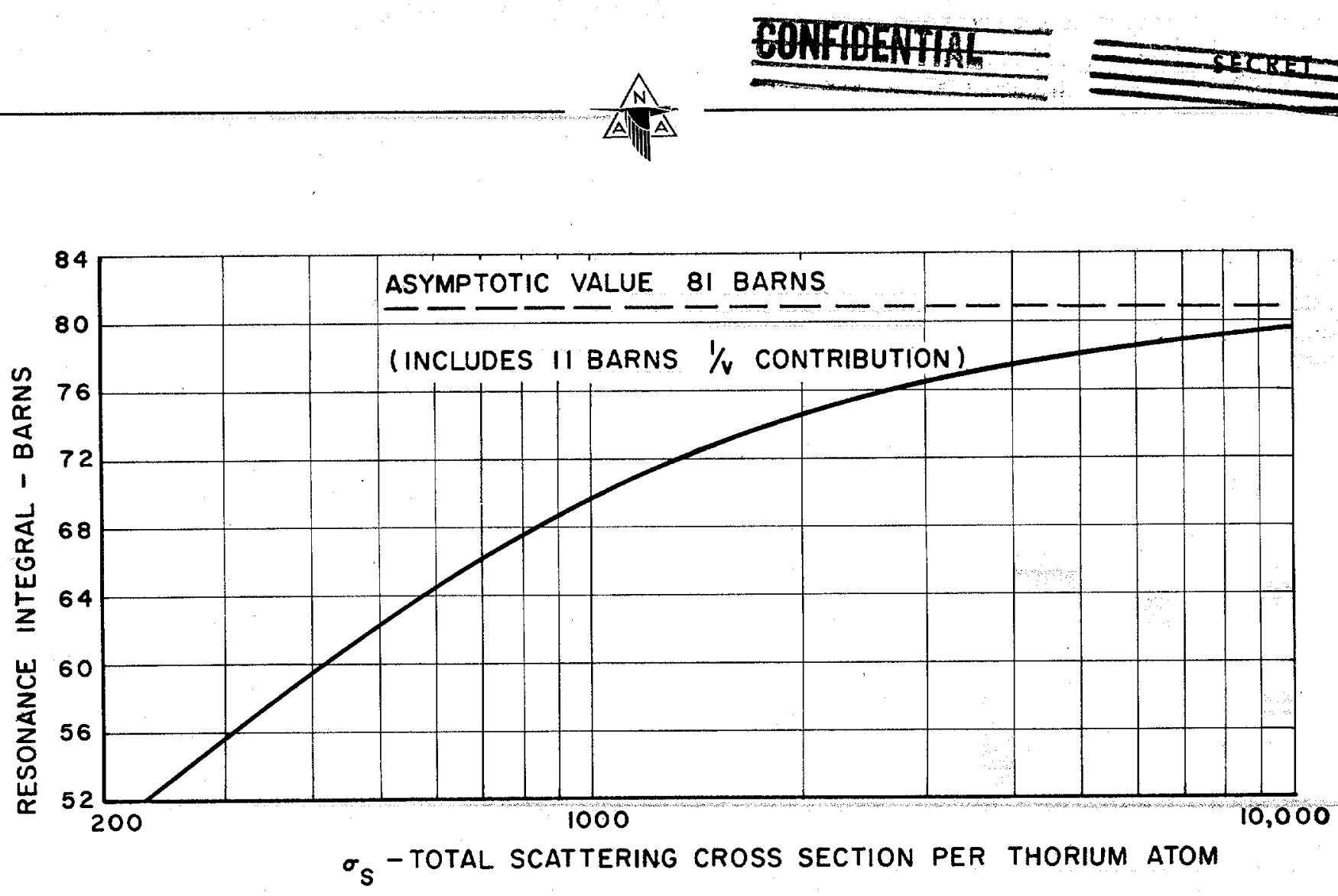

FIG. 1. THORIUM RESONANCE INTEGRAL VS SCATTERING CROSS SECTION

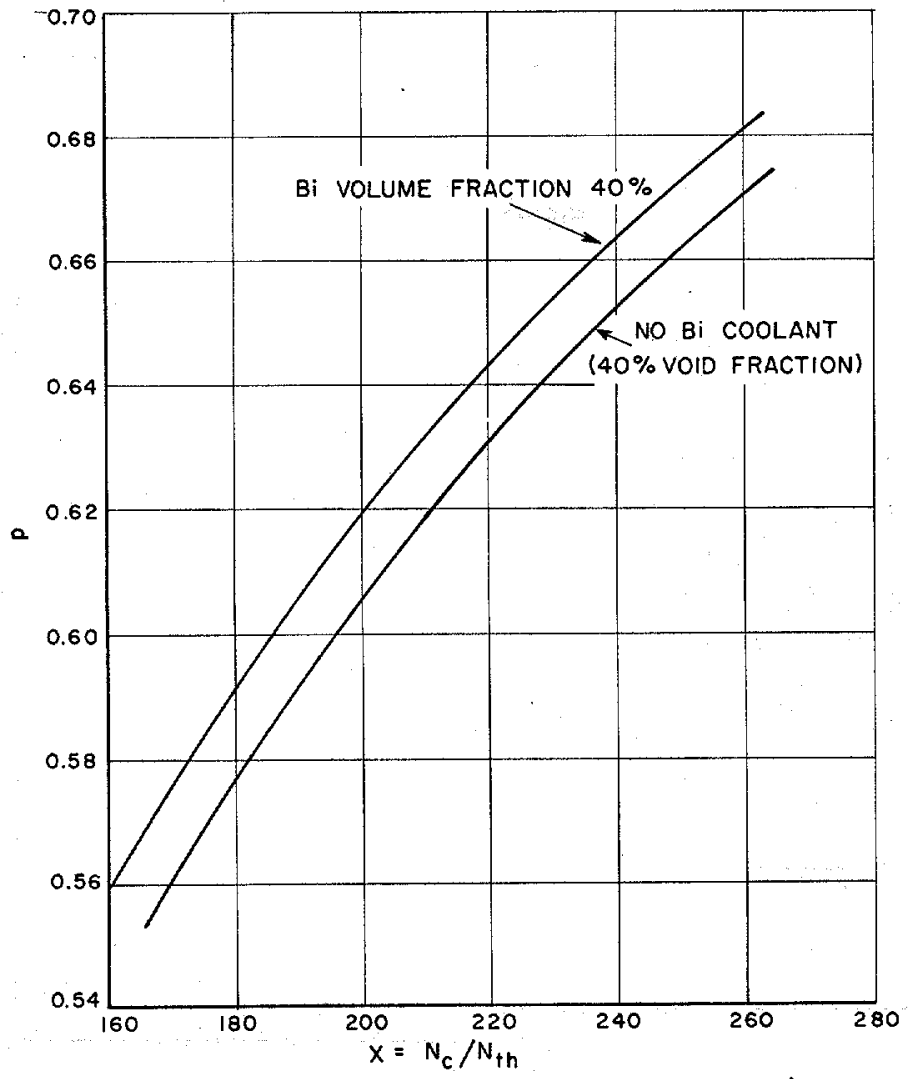

FIG. 2. RESONANCE ESCAPE PROBABIUITY VS THORIUM CONCEQRRATION IN GRAPHITE 


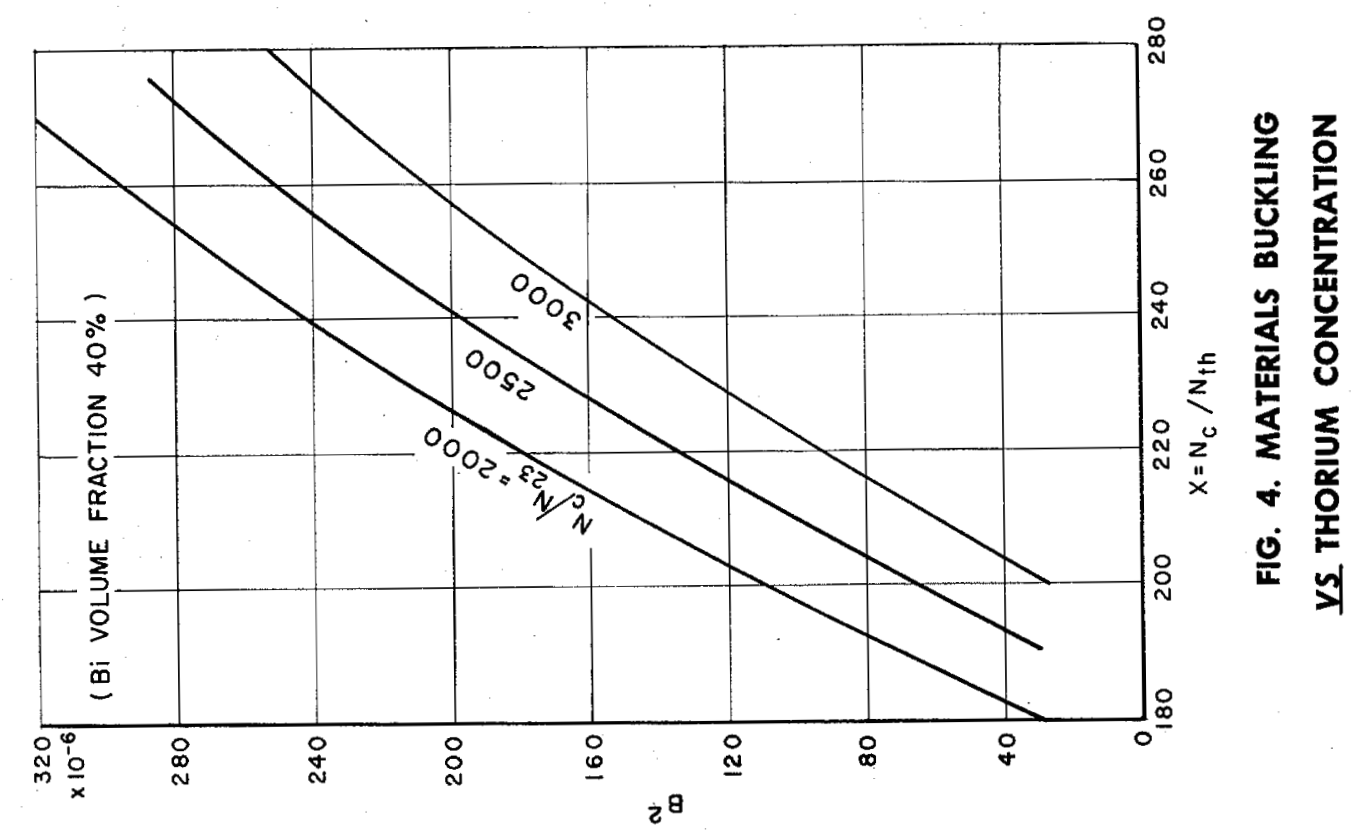

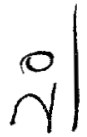

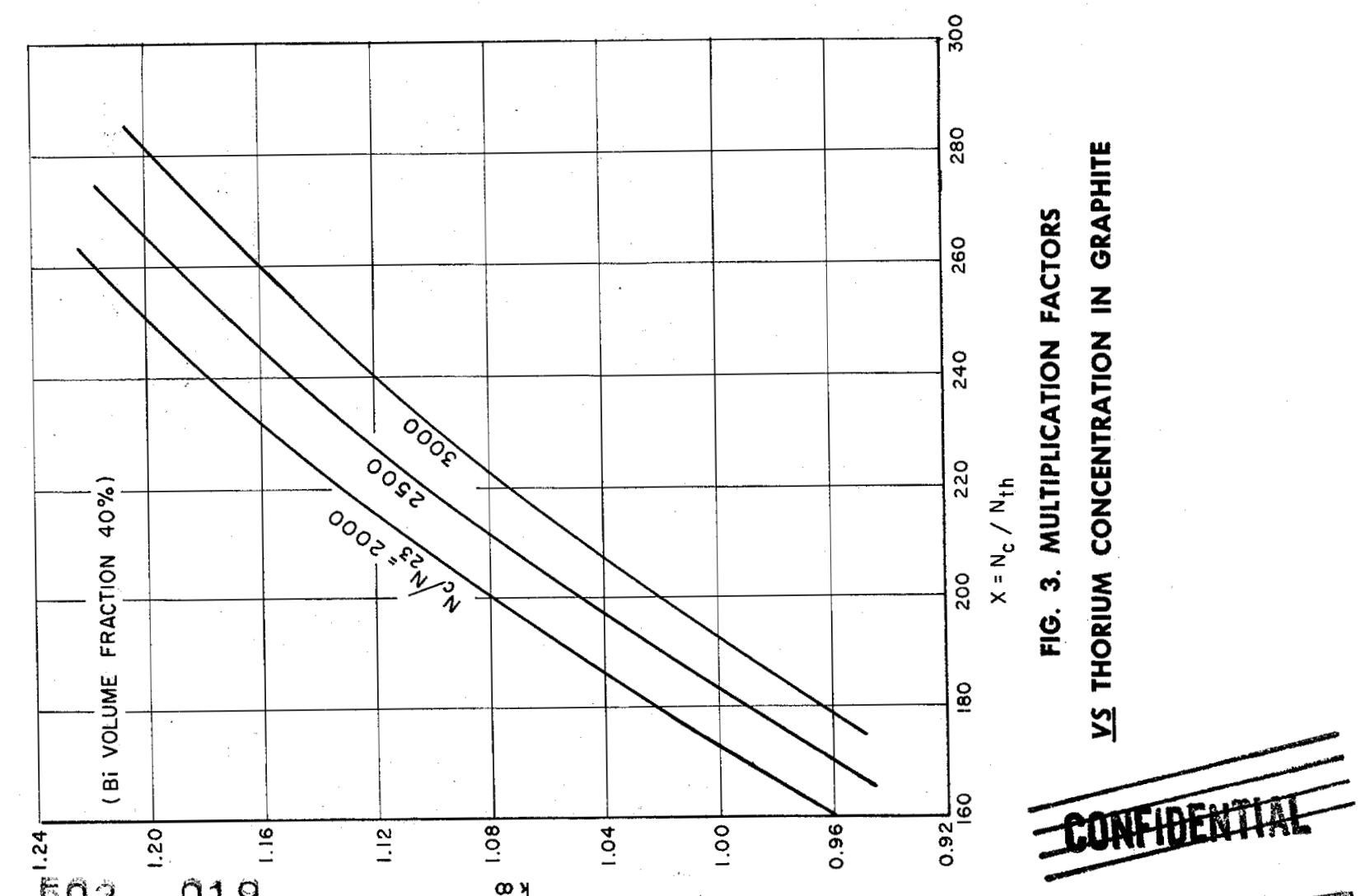




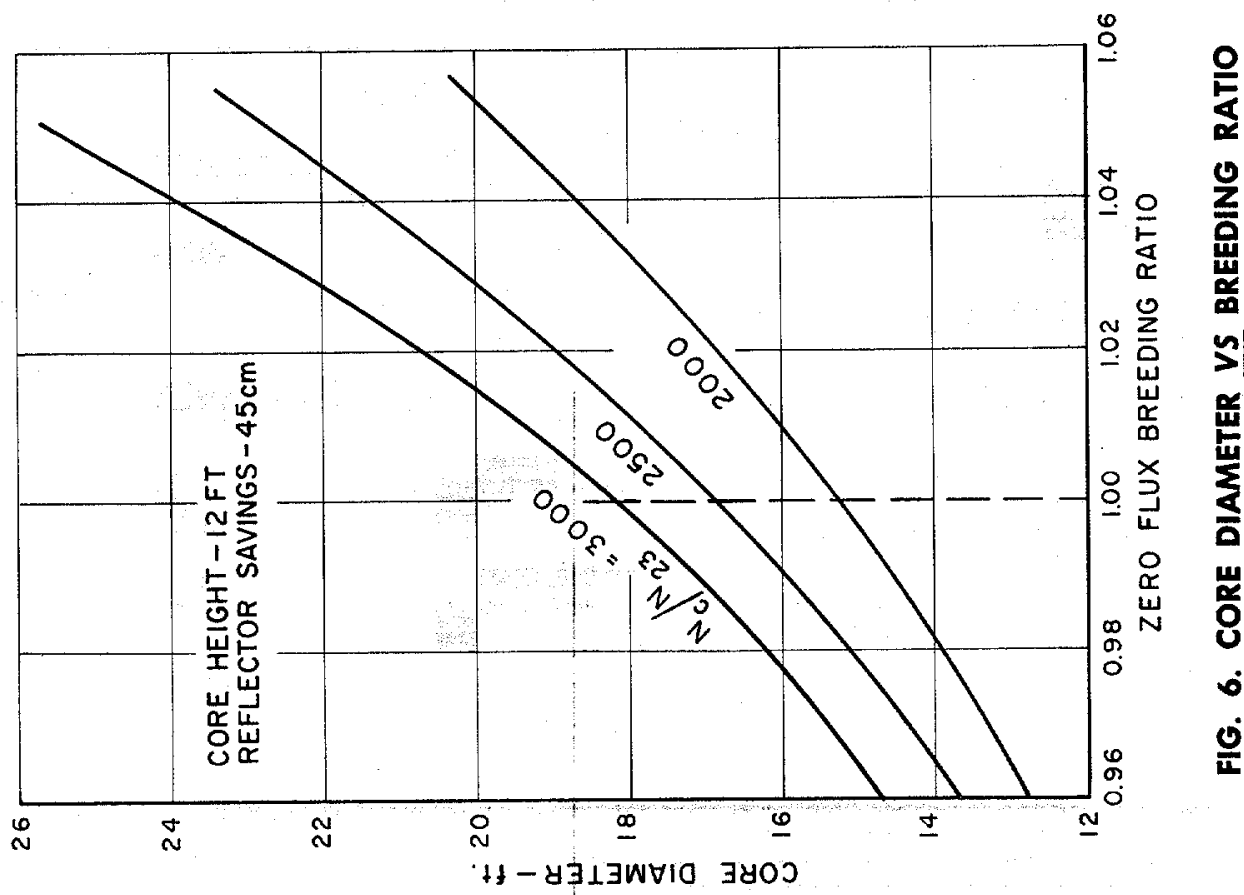

$\gamma$

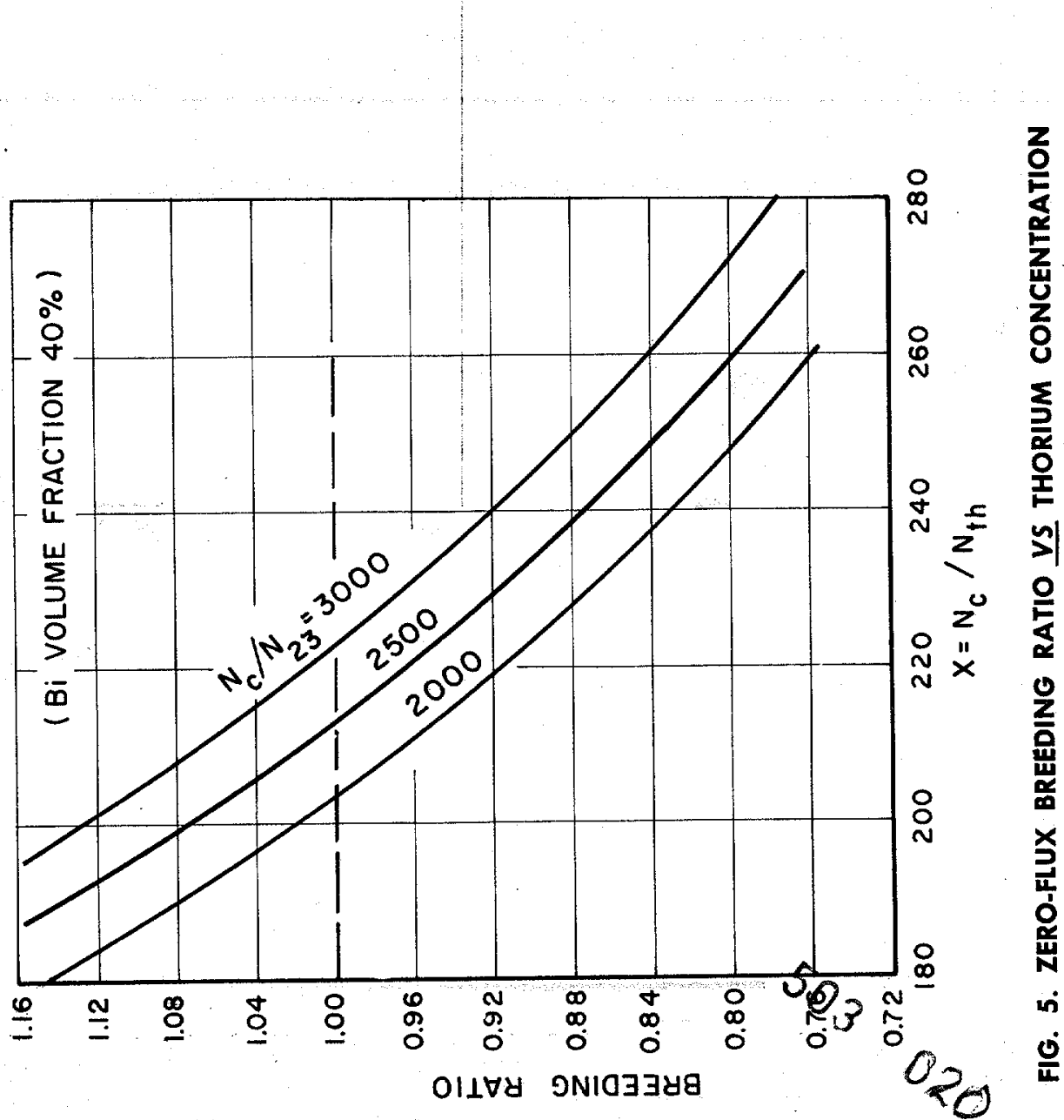




\section{REFERENCES}

1. Carman, P. C., "Fluid Flow Through Granular Beds," Trans. Inst. Chem. Engrs. (London), 15, 150-166, (1937).

2. Halperin, J., et al., "Capture Cross Section of $\mathrm{Pa}^{233}$ for Thermal Reactor Neutrons," RST 3, No. 3 (TID-2010), September 1953, pages 108-11.

3. Timoshenko, S. and J. N. Goodier, Theory of Elasticity, 2nd Ed., Mc GrawHill, New York, 1951 .

4. The Reactor Handbook Vol. 3, 1st Ed., TIS USAEC, Oak Ridge, Tennessee, 1953, Chapter 1.9.

5. Perry, J. H., Chemical Engineer's Handbook, 3rd Ed., Mc Graw-Hill, New York, 1950, page 393.

6. Lyon, R. N., Liquid Metals Handbook, 2nd Ed. (Rev.), Department of the Navy, 1952.

7. Fahrner, T., et al.,"A Sodium Cooled, Low Enrichment Uranium Reactor for the Production of Plutonium and Useful Power," NAA-SR-180, March, 1953.

8. Isotopics, 3, No. 4, (October, 1953).

9. Gurinsky, D. H., et al., "Preliminary Study of a Uranium-Bismuth Liquid Fuel Power Reactor LFR 2," BNL-111, June 5, 1951.

10. Shapiro, A. H., et al., "Power Plants with Thermal Reactors, An Economic and Engineering Analyses," MIT-5003, September 15, 1953.

$503 \quad 021$ 